\title{
ANÁLISE DA CONCENTRAÇÃO DE AMÔNIA EM GALPÕES DE FRANGO DE CORTE SUBMETIDOS A DIFERENTES DIETAS
}

Keles Regina Antony Inoue ${ }^{1}$, Ilda Ferreira de Fátima Tinôco², Déborah Cunha Cassuce ${ }^{3}$, Mateus Marques Bueno ${ }^{4}$, Alfredo Lora Graña ${ }^{5}$

\section{RESUMO}

O apelo ambiental à redução de gases nocivos ao meio ambiente vem gerando uma adaptação aos meios de produção e a criação de novos modelos. Objetivou - se com o estudo monitorar a concentração de amônia, em um galpão experimental para frangos de corte, localizado no Departamento de Zootecnia da UFV, com 800 aves distribuídas em 40 boxes, sendo 20 aves em cada boxe, submetidas a cinco diferentes rações, que constituíram os tratamentos e 4 repetições. $T_{1}$ Ração com elevado nível de proteína e suplementação mínima de aminoácidos; $\mathrm{T}_{2}$ Ração baseada no conceito de proteína ideal; $\mathrm{T}_{3}$ $T_{1}$ com suplementação de Fitase; $T_{4-} T_{1}$ com suplementação de minerais orgânicos e; $T_{5}$ combinação dos tratamentos $T_{2}$, $\mathrm{T}_{3} \mathrm{e} \mathrm{T}_{4}$. O Monitoramento da concentração de amônia nos diferentes tratamentos foi realizado com sensor eletroquímico da marca Quest, modelo Safecheck 100. As maiores concentrações de amônia foram detectadas nas últimas semanas antes do abate, em função do desenvolvimento das aves. Maiores níveis foram encontrados no $T_{1}$ e menores níveis de nos $\mathrm{T}_{2}$ e $\mathrm{T}_{5}$. Os tratamentos, compostos de proteína ideal $\left(\mathrm{T}_{2}\right.$ e $\left.\mathrm{T}_{5}\right)$, que ofereceram um melhor perfil aminoacídico, favoreceram a redução da perda de nitrogênio, o que reduziu a produção de ácido úrico na cama e, conseqüentemente, a emissão de amônia no galpão. A adição da fitase e minerais orgânicos aumentaram a disponibilidade da proteína para o organismo do animal. A concentração máxima de amônia recomendada internamente às instalações é de 20 ppm, sendo assim, em nenhum dos tratamentos observou-se níveis médios superiores aos limites permitidos para os animais.

Palavras-chave: amônia, poluição do ar, nutrição

\section{ABSTRACT}

\section{AMMONIA CONCENTRATION IN BROILER CHICKEN BARNS FED WITH DIFFERENT DIETS}

The environmental concerns regarding emission reduction of harmful gases has lead to adaptation of novel means of production and new models. The objective of this study was to monitor the concentration of ammonia in an experimental broiler chicken shed, located in the Department of Animal Science, UFV, with 800 birds distributed in 40 boxes, each with 20 birds. The birds were fed five different diets, constituting the treatments, with four replications. T1 - Diet with high protein and minimal amino acid supplementation, $\mathrm{T} 2=$ diet based on the concept of optimal protein; T3 - T1 with phytase supplement; T4 - T1 with organic mineral supplement and; T5- combination of T2, T3 and T4. The Concentration of ammonia was monitored with the use of electrochemical sensor (Quest model Safecheck 100). Data were analyzed with help of SAEG computer program, developed by the University Federal of Viçosa (UFV, 2000). Regression analysis was done at $5 \%$ probability. In general, the highest concentrations of ammonia were found in the last week before slaughter, depending on the development of birds. Highest levels of ammonia were found when birds were fed T1 and the lowest when fed T2 and T5. The treatments, consisting of ideal protein (T2 and T5), which has better amino acid profile, reduced nitrogen loss, resulting in reduced production of uric acid in bed, thus reducing ammonia emission. The addition of phytase and organic minerals increased availability of protein. The recommended maximum concentration of ammonia inside the shed is $20 \mathrm{ppm}$, and in none of the treatments the concentration reached above thus limit.

Keywords: air quality, nutrition

\footnotetext{
Recebido para publicação em 16/04/2010. Aprovado em 02/09/2011.

1- Engenheira Agrônoma, Doutoranda em Eng. Agrícola, UFV, Viçosa-MG, Brasil, kelesreina@hotmail.com

2- Engenheira Agrícola, Professora Associada, DEA, UFV, Viçosa-MG, Brasil

3- Zootecnista, Professora Substituta, UFV, Rua PH, Viçosa-MG, Brasil

4- Engenheiro Agrícola UFV, Viçosa-MG, Brasil

5- Zootecnista, UFV, Viçosa-MG, Brasil
} 


\section{INTRODUÇ̃̃O}

Com a modernização e desenvolvimento da avicultura brasileira, assim como a mundial, rapidamente tem-se alcançado altos níveis de produtividade. Em 1970, eram necessários 70 dias para o crescimento e engorda de frango de corte que consumia cerca de $2,0 \mathrm{~kg}$ de ração para $1,0 \mathrm{~kg}$ de ganho de peso; atualmente um frango de corte chega ao abate com $2,4 \mathrm{~kg}$ de peso vivo, aos 42 dias com conversão alimentar de $1,8 \mathrm{~kg}$ de ração por kg de ganho de peso (NEVES et al., 2007).

A produção brasileira de frangos de corte atingiu volumes, tanto de produção quanto de exportação, que se destacaram pela geração de renda ao meio rural, e pela oferta de uma fonte de proteína de alta qualidade para a população (UBA, 2006).

A qualidade do ar é um fator muito importante para a produção avícola, pois influencia diretamente o bem-estar animal e dos tratadores, podendo causar danos ao meio ambiente quando em níveis elevados de emissão de gases nocivos. Os principais reflexos ambientais relacionados à emissão e dispersão de gases, a partir das instalações de produção animal, referem-se à deposição de ácido, aquecimento global e efeitos locais e regionais da emissão de odores (MIRAGLIOTTA, 2005).

O confinamento dos animais em instalações fechadas aumenta o potencial de intoxicação por gases, com a presença mais comum de monóxido de carbono ( $\mathrm{CO})$, dióxido de carbono $\left(\mathrm{CO}_{2}\right)$ e amônia $\left(\mathrm{NH}_{3}\right)$, que é apontada como o principal gás que afeta negativamente as aves e os tratadores (LIMA et al. 2004).

Questões ambientais, segurança alimentar e o bem estar animal estão diretamente relacionados à qualidade do ar, pois os poluentes aéreos alteram as características ideais do ar, e favorecem o aumento de doenças respiratórias e prejuízos no processo produtivo das aves. (MACARI; FURLAN, 2001; TINÔCO, 2004, TINÔCO; GATES, 2005).

A ocorrência de doenças causadas, desencadeadas ou agravadas pela baixa qualidade do ar, tem impacto econômico tanto em virtude das ações diretas da interação entre o organismo patogênico e o animal, como pelo fato de que a baixa qualidade do ar é um fator estressante para o animal.
Dentre os gases normalmente encontrados no interior das instalações avícolas destacam-se a amônia, o monóxido e dióxido de carbono (LIMA, 2004).

A geração de amônia nos galpões avícolas é decorrente da decomposição microbiana do ácido úrico dos excrementos sobre a cama, tendo sua liberação influenciada pela umidade da cama (FURLAN, 2006). É um gás incolor, de forte odor, extremamente nocivo e gerado em abundância na referida atividade. Os efeitos mais comuns da exposição à amônia são irritação de mucosas dos olhos e das vias respiratórias e, posteriormente, quando cai na corrente sanguínea, tem efeito tóxico sobre o metabolismo fisiológico (CURTIS, 1983).

Os cuidados relativos à emissão de amônia das instalações animais não se restringe apenas ao ambiente interno, uma vez que a amônia provoca efeitos severos ao meio ambiente, como acidificação e eutrofização (TINÔCO; GATES, 2005).

A redução de proteína bruta na dieta e o uso de aminoácidos sintéticos como lisina, treonina e metionina pode melhorar a qualidade do ar nos galpões, uma vez que ocorre um melhor aproveitamento do nitrogênio e conseqüente redução de sua liberação para o ambiente.

$\mathrm{O}$ fósforo $(\mathrm{P})$ é o mineral de custo mais elevado, representando cerca de 2 a $2,5 \%$ do custo total da ração. Nos alimentos de origem vegetal, utilizados nas rações avícolas, 60 a $85 \%$ do fósforo se encontram, em sua maior parte, na forma de fitato, isto é, indisponível para as aves. O fitato, que não é digerido pelas aves, é eliminado nas fezes, contribuindo para o aumento da poluição ambiental (ROSTAGNO et al., 2005). O aumento da atividade da fitase aumenta a disponibilidade do fósforo. Além do Fósforo, o fitato pode reduzir também a disponibilidade da proteína, uma vez que inibe a atividade de enzimas proteolíticas. Espera-se que o uso de fitase na ração aumente a disponibilidade de fósforo e nitrogênio, reduzindo a excreção para o meio ambiente.

Assim como a fitase, os minerais orgânicos aumentam a disponibilidade da proteína, devido ao melhor aproveitamento da dieta, tornando possível o melhor aproveitamento do perfil de aminoácidos e conseqüente redução do nitrogênio nas excretas. 
O conhecimento das condições de qualidade do ar, bem como o desenvolvimento de tecnologias para que se possa reduzir a emissão dos gases presente nas instalações para a produção animal é uma necessidade da atualidade e urgente. Diante dos argumentos expostos, o trabalho foi realizado com o objetivo de quantificar a concentração de amônia em galpões de frangos submetidos a diferentes dietas.

\section{MATERIAL E MÉTODOS}

A pesquisa foi conduzida no período de 31 de agosto a 13 de outubro de 2006, em um galpão experimental de frangos de corte, localizado no Departamento de Zootecnia da Universidade Federal de Viçosa, em Viçosa-MG, localizada em latitude de $20^{\circ} 45^{\prime} 45^{\prime \prime}$ sul e longitude $42^{\circ} 52^{\prime} 04^{\prime \prime}$ oeste. O clima da região, de acordo com a classificação de Koppen, é Cwa (quente, temperado, chuvoso, com estação seca no inverno e verão quente).

As aves foram alojadas em um galpão de alvenaria dividido em 40 boxes $(1,0 \times 2,0 \mathrm{~m})$, pé direito de $3 \mathrm{~m}$ de altura, cobertura de telhas de amianto, piso cimentado, paredes laterais constituídas por mureta de $0,40 \mathrm{~m}$ e o restante telado, dotado de lanternim e cortinas plásticas para o controle da temperatura e correntes de ar. Foi utilizado cepilho de madeira como material de cama.

Em cada boxe foram alojados 20 frangos de corte, machos, da linhagem comercial Cobb-500, no período de 1 a 46 dias de idade, com peso médio inicial de 43,63 g. O manejo geral das aves foi de acordo com o manual da linhagem utilizada, recebendo alimentação e água à vontade. $\mathrm{O}$ sistema de aquecimento disposto para as aves foi por meio de lâmpadas incandescentes de $250 \mathrm{w}$ instaladas no centro de cada boxe, tendo a altura regulada conforme o crescimento dos animais. $\mathrm{O}$ delineamento experimental utilizado foi em blocos casualisados, com 4 repetições.

A ração fornecida aos animais foi desenvolvida pelo Departamento de Zootecnia da Universidade Federal de Viçosa - UFV, conforme as exigências nutricionais de cada fase de desenvolvimento das aves. As rações foram formuladas a base de milho e farelo de soja. Somente na fase pré-inicial também foram adicionados farinha de peixe e farelo de glúten de milho. As exigências nutricionais, para cada fase, seguiram as recomendações de Rostagno et al. (2005). Sendo assim, formulou-se cinco rações, que constituíam os tratamentos experimentais. Tratamento um $\left(\mathrm{T}_{1}\right)$ era composto por ração com elevado nível de proteína e suplementação mínima de aminoácidos; tratamento dois $\left(\mathrm{T}_{2}\right)$ Ração baseada no conceito de proteína ideal; Tratamento três $\left(\mathrm{T}_{3}\right) \mathrm{T}_{1}$ com suplementação de Fitase na dieta; Tratamento quatro $\left(\mathrm{T}_{4}\right) \mathrm{T}_{1}$ com suplementação de minerais orgânicos ( $\mathrm{Cu}, \mathrm{Zn} \mathrm{Mn})$ e; Tratamento cinco $\left(\mathrm{T}_{5}\right)$ combinação dos tratamentos $\mathrm{T}_{2}, \mathrm{~T}_{3} \mathrm{e} \mathrm{T}_{4}$. Cada linha de boxe representava um bloco experimental, contendo os cinco tratamentos. As medidas das concentrações instantâneas de amônia $\left(\mathrm{NH}_{3}\right)$ foram feitas em todo o período experimental. Com três dias de tomada de dados na primeira fase (1-8 dias), quatro dias para a segunda (9-21 dias), terceira (2233 dias) e quarta (34-42 dias) fase e finalizando com três dias para a quinta fase (43-46 dias). As medidas foram feitas em cada tratamento e sempre acompanhando a altura das aves. As medidas da concentração de amônia foi realizada três vezes ao dia, nos horários de 9:00 h, 12:00 h e 15:00 h.

Para detecção das concentrações de amônia utilizou-se um sensor da marca Quest, modelo Safecheck 100, de princípio eletroquímico, com resolução de $1 \mathrm{ppm}$ e acuraria $\pm 1 \mathrm{ppm}$, que detecta a concentração de $\mathrm{NH}_{3}$ numa faixa de medição de 0 a 100 ppm (Figura 1). As análises estatísticas foram realizadas por meio de análise de regressão, com 5\% probabilidade. O programa computacional utilizado foi o SAEG (Sistema para Análises Estatísticas e Genéticas), desenvolvido pela Universidade Federal de Viçosa (UFV, 2000).

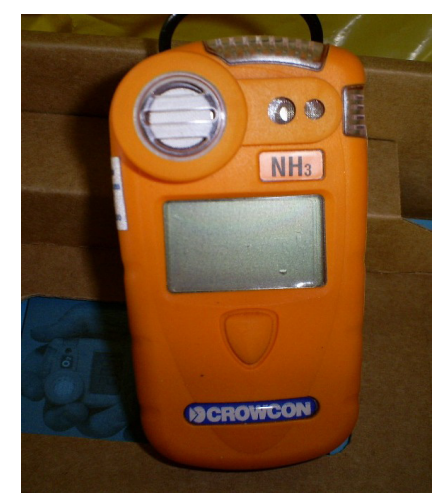

Figura 1. Unidade de aquisição de dados de amônia, utilizada no experimento. 


\section{RESULTADOS E DISCUSSÃO}

No Quadro 1, estão apresentadas as equações de regressão para cada tratamento, com seus respectivos $\mathrm{R}^{2}$.

Como pode ser observado na Figura 2, as concentrações médias instantâneas de amônia para todos os diferentes tratamentos avaliados foram crescentes com o desenvolvimento das aves. Esse aumento $(\mathrm{P}<0,05)$, foi maior nos tratamentos $1 \mathrm{e}$ 3 , sendo que os valores mais elevados ocorreram no tratamento 3 .

No Quadro 2, estão apresentados os valores médios da concentração de amônia nas diferentes dietas fornecidas para as aves, nas 5 fases de crescimento (semanas de idade).

A Figura 2 informa ainda que os menores níveis de concentração de amônia foram detectados no tratamento 5 , composto por proteína ideal, fitase e minerais orgânicos, seguido do tratamento 2 , que foi baseado somente na proteína ideal. Isso ocorreu provavelmente em função da proteína ideal, que fornece melhor perfil aminoacídico ao animal, favorecendo a redução da perda de nitrogênio e da produção deácido úrico na cama e, conseqüentemente, reduz a emissão de amônia pelas aves.

Quadro 1. Equações de regressão, com respectivos coeficientes de determinação, para estimativa da concentração de amônia $\left(\mathrm{NH}_{3}\right)$, para as 5 fases de crescimento estudadas

\begin{tabular}{ccc}
\hline Tratamento & Equações Ajustadas & $\mathbf{R}^{2}$ \\
\hline 1 & $\hat{y}=0,327392-0,119334 \mathrm{x}+0,689982 \mathrm{x}^{2}$ & 0,93 \\
2 & $\hat{y}=0,36117-0,112010 \mathrm{x}+0,601744 \mathrm{x}^{2}$ & 0,84 \\
3 & $\hat{y}=-0,496349+0,192571 \mathrm{x}+0,454466 \mathrm{x}^{2}$ & 0,90 \\
4 & $\hat{y}=0,615222-0,751533 \mathrm{x}+0,554190 \mathrm{x}^{2}$ & 0,88 \\
5 & $\hat{y}=0,232134-0,899890 \mathrm{x}+0,546263 \mathrm{x}^{2}$ & 0,89 \\
\hline
\end{tabular}

Quadro 2. Concentrações médias de amônia nos diferentes tratamentos utilizados no experimento e para cada fase de crescimento: 1 (1-8 dias), 2 (9-21 dias), 3 (22-33 dias), 4 ( 34 a 42 dias) e 5 ( $43-46$ dias)

\begin{tabular}{cccccc}
\hline Tratamento & Fase 1 & Fase 2 & Fase 3 & Fase 4 & Fase 5 \\
\hline T1 & 0,0 & 0,0 & 1,92 & 6,47 & 8,11 \\
T2 & 0,0 & 0,0 & 1,47 & 5,36 & 6,96 \\
T3 & 0,0 & 0,0 & 3,08 & 6,78 & 7,85 \\
T4 & 0,0 & 0,0 & 2,03 & 5,69 & 7,22 \\
T5 & 0,0 & 0,0 & 2,03 & 4,58 & 7,0 \\
\hline
\end{tabular}

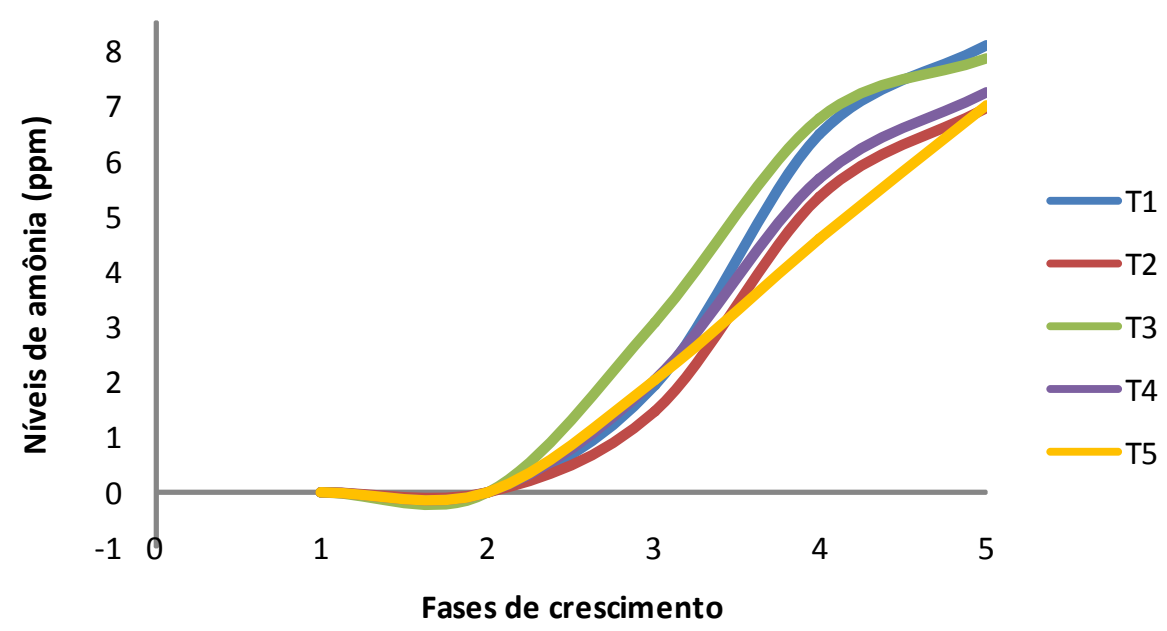

Figura 2. Concentrações médias de amônia $\left(\mathrm{NH}_{3}\right)$ em ppm, observados nos diferentes tratamentos e avaliados para cada fase de crescimento das aves. 
Os resultados corroboram com os resultados de Ferguson et al. (1998), que verificaram redução na concentração de $\mathrm{NH}_{3}$ nas instalações avícolas, quando as formulações da ração possuía níveis baixos de proteína. Gates (2000), estudando frangos de corte, verificou que após três lotes de criação utilizando a mesma cama, as aves que receberam o tratamento com alto nível de proteína tiveram maiores concentrações de $\mathrm{NH}_{3}$. O autor sugere que a formulação de rações com a redução protéica pode ser utilizada com o objetivo de controlar a excreção de nitrogênio (N) e, conseqüentemente, da amônia $\left(\mathrm{NH}_{3}\right)$ dentro das instalações.

O tratamento 4, contendo minerais orgânicos, resultou em níveis intermediários de amônia quando comparado com os tratamentos 2 e 3 . A utilização dos minerais orgânicos aumenta a disponibilidade dos nutrientes em que eles se ligam. Sendo assim, aumenta a disponibilidade da proteína, o que leva a uma redução da formação de amônia devido à excreção da proteína.

A utilização da fitase na dieta (tratamento 3), favorece a disponibilidade do fósforo e da proteína presente na alimentação dos animais. Dessa forma, a introdução da fitase na composição da ração pode reduzir a excreção de nitrogênio nas fezes, bem como para o meio ambiente.

A fitase e a xilanase, quando presentes na ração, levam a produção de esterco com níveis reduzidos de nitrogênio $(\mathrm{N})$ e fósforo $(\mathrm{P})$, resultando em menos óxido nitroso $\left(\mathrm{N}_{2} \mathrm{O}\right)$ na atmosfera, o que contribui para a redução do aquecimento global. Além disso, níveis elevados de amônia $\left(\mathrm{NH}_{3}\right)$, nitrato $\left(\mathrm{NO}_{2}\right)$ e fosfato $\left(\mathrm{PO}_{4}\right)$ entram no meio ambiente causando acidificação e eutrofização (PETTERSSON, 2007).

Segundo Wathes (1998), a concentração máxima de amônia recomendada em instalações é de 20 ppm. Não foi observado em nenhum dos tratamentos, níveis de emissão superiores aos limites permitidos para os animais; entretanto, os tratamentos 1, 3 e 4, apresentaram níveis de concentração de amônia superiores aos tratamentos 5 e 2 .

\section{CONCLUSÕES}

- A concentração dos gases, mensurados nos ambientes de aves submetidas a diferentes estratégias nutricionais, não apresentaram valores prejudiciais, estando dentro dos limites aceitáveis; e

- As maiores concentrações de gases ocorreram nos lotes tratados com proteína bruta, sendo que as menores concentrações foram verificadas nas dietas formuladas com menores níveis de proteína e adição de enzimas e minerais orgânicos.

\section{REFERÊNCIAS BIBLIOGÁFICAS}

BRANDJES, P.J.; WIT, de J.; VAN DE MEER, H.G.; and VAN KEULEN, H. Livestock and environment finding a balance: Environmental impact of animal manure management. Wageningen: the Netherlands. International Agricultural Centre, 1996. 52p.

CASTRO, A.G.M. Importância do controle de doenças respiratórias em codornas. In: III RIFIB - Reunião Itinerante de Fitossanidade do Instituto Biológico, 3., 2000, Mogi das Cruzes, SP. Anais... III Reunião Itinerante de Fitossanidade do Instituto Biológico, Mogi das Cruzes: v. 3, 2000. p.94-96.

CURTIS, S.E. Environmental management in animal agriculture. AMES: The Iowa State University Press, 1983. 409p.

FERGUSON, N.S.; GATES, R S,; TARABA, J. L. et al. The effect of dietary crude protein on growth, ammonia concentration and litter composition in broilers. Poultry Sci., Illinois, 77, 1998. 1481-1487.

GATES, R.S. Poultry Diet Manipulation to Reduce output of polulants to environment. In: Simpósio sobre Resíduos da Produção Avícola. Embrapa. 2000, Concórdia, Santa Catarina. Anais... Concórdia. SC, 2000. p.63-75.

LIMA, A.M.C., NÄÄS, I.A., BARACHO, M.S., MIRAGLIOTTA, M.Y. Ambiência e bem-estar. 
In: Produção de frangos de corte. 1 ed. Campinas: FACTA, 2004. 356p.

LIMA, A.M.C.; NÄÄS, I.A.; BARACHO, M.S.; MIRAGLIOTTA, M.Y. Produção de frangos de corte. 1 ed. Campinas: FACTA. 2004. 356p.

MACARI, M; FURLAN, R.L. Ambiência na produção de aves em clima tropical. 1 ed. Piracicaba - SP: Editado por Iran José Oliveira da Silva, 2001. 31-87p.

MIRAGLIOTTA, M.Y. Avaliação das condições do ambiente interno em dois galpões de produção comercial de frangos de corte, com ventilação e densidade populacional diferenciados. 2005. 244f. Tese (Doutorado em Engenharia Agrícola, na área de concentração de Construções Rurais e Ambiência). Universidade Estadual de Campinas UNICAMP, 2005.

NEVES, D.P.; SILVEIRA, N.A.; SILVA, R.B.T.R. O papel do designer na avicultura de corte brasileira. In: Congresso Internacional De Pesquisa em Design, 4., 2007, Rio de Janeiro. Anais... Rio de Janeiro, 2007. 1-1p.

NIOSH - National institute for occupational safety and health. Versão eletrônica, 2003. Disponível em: <http://cdc.gov/niosh/pel88/766441.html $>$. Acesso em 19 de julho de 2005.

PETTERSSON, D. Reduzindo as pegadas de carbono de Mr. Piggy. Biotimes ${ }^{\circledR}, 2007$. Disponível em: <http://www.novozymes.com/ NR/rdonlyres/4C86A02A-C2EA-445C-A271-
6C1FA4D7DC2F/0/PT_reducing.pdf $>$. Acesso em: 13 fev. 2008.

ROSTAGNO, H.S.; ALBINO L.F.T.; DONZELE, J.L,; et al. Tabelas brasileiras para aves e suínos: composição de alimentos e exigências nutricionais. 2 ed. Viçosa - MG: Universidade Federal de Viçosa. 2005, 186p.

TINÔCO, I.F.F. A granja de frangos de corte. Produção de frangos de corte. 1 ed. Campinas: FACTA, 2004. 356p.

TINÔCO, I.F.F. \& GATES, R.S. Ambiência e Construções para Matrizes Pesadas. In: Manejo de Matrizes de Corte. 1 ed. Campinas: FACTA 2005. 414p.

UBA. Relatório anual 2005/2006. Disponível em: $\quad<$ http://www.uba.org.br/ubanews_files/rel_ uba_2005_06.pdf >. Acesso em: 10 Jan. 2007.

VIGODERIS, R.B. Sistemas de aquecimento de aviários e seus efeitos no conforto térmico ambiental, qualidade do ar e performance animal, em condições de inverno na região sul do Brasil. 2006. 104 f. Tese (Doutorado em Engenharia Agrícola) - Universidade Federal de Viçosa, UFV, 2006.

WATHES, C.M. Aerial emissions from poultry production. World Poultry Science Journal, 54: 1998. 241- 251p.

WATHES, C.M. Strive for clean air in your poultry house. World Poultry, Surrey, v. 15, n.3,1999. 17-19p. 